This item was submitted to Loughborough's Research Repository by the author.

Items in Figshare are protected by copyright, with all rights reserved, unless otherwise indicated.

\title{
Effects of small-sided games vs. conventional endurance training on endurance performance in male youth soccer players: A meta-analytical comparison
}

\section{PLEASE CITE THE PUBLISHED VERSION}

https://doi.org/10.1007/s40279-019-01086-w

\section{PUBLISHER}

Springer Nature Switzerland AG

\section{VERSION}

VoR (Version of Record)

\section{PUBLISHER STATEMENT}

This work is made available according to the conditions of the Creative Commons Attribution-NonCommercialNoDerivatives 4.0 International (CC BY-NC-ND 4.0) licence. Full details of this licence are available at: https://creativecommons.org/licenses/by-nc-nd/4.0/

\section{LICENCE}

CC BY-NC-ND 4.0

\section{REPOSITORY RECORD}

Moran, Jason, Richard Blagrove, Benjamin Drury, John F.T. Fernandes, Kevin Paxton, Helmi Chaabene, and Rodrigo Ramirez-Campillo. 2019. "Effects of Small-sided Games Vs. Conventional Endurance Training on Endurance Performance in Male Youth Soccer Players: A Meta-analytical Comparison". figshare. https://hdl.handle.net/2134/38337. 
Effects of small-sided games versus conventional endurance training on endurance performance in male youth soccer players: a meta-analytical comparison

Short title: Effects of SSGs vs CET on endurance in young male soccer players

Jason Moran ${ }^{1}$

Richard C. Blagrove ${ }^{2}$

Benjamin Drury ${ }^{1}$

John F.T. Fernandes ${ }^{1}$

Kevin Paxton ${ }^{3}$

Helmi Chaabene $e^{4,5}$

Rodrigo Ramirez-Campillo ${ }^{6}$

1. Department of Sport, Hartpury University, Gloucestershire, United Kingdom

2. Department of Sport and Exercise, Birmingham City University, Birmingham, United Kingdom

3. Leicester City Football Club, Leicester, United Kingdom

4. Division of Training and Movement Science, University of Potsdam, Potsdam, Germany

5. High Institute of Sports and Physical Education, University of Jendouba, Kef, Tunisia

6. Universidad de Los Lagos (University of Los Lagos), Department of Physical Activity Sciences, Research Nucleus in Health, Physical Activity and Sport, Laboratory of Measurement and Assessment in Sport, Osorno, Chile

Corresponding author contact details: jason.moran@hartpury.ac.uk, +44 1452702482 


\begin{abstract}
Background: Small sided games (SSGs) have been suggested as a viable alternative to conventional endurance training (CET) to enhance endurance performance in youth soccer players. This has important implications for long-term athlete development because it suggests that players can increase aerobic endurance through activities that closely resemble their sport of choice.
\end{abstract}

Objectives: This meta-analysis compared male youth soccer players' adaptability to SSG vs. CET and sought to establish exercise prescription guidelines for this population.

Data sources: The data sources utilised were Google Scholar, PubMed and Microsoft Academic.

Study eligibility criteria: Studies were eligible for inclusion if interventions were carried out in male soccer players (<18 years) and compared the effects of SSG and CET on aerobic endurance performance. We defined SSG as "modified [soccer] games played on reduced pitch areas, often using adapted rules and involving a smaller number of players than traditional games". We defined CET as continuous running or extensive interval training consisting of work durations $>3$ mins.

Study appraisal and synthesis methods: The inverse-variance random effects model for meta-analyses was used because it allocates a proportionate weight to trials based on the size of their individual standard errors and facilitates analysis whilst accounting for heterogeneity across studies. Effect sizes (ES) were represented by the standardised mean difference and presented alongside $95 \%$ confidence intervals (Cl). 
Results: Seven studies were included in this meta-analysis. Both modes of training were effective in increasing endurance performance. Within-mode ESs were both of moderate magnitude (SSG: 0.82 [95\% confidence interval $[\mathrm{Cl}]: 0.05,1.60], \mathrm{Z}=2.07$ [p = 0.04]; CET: 0.89 [95\% Cl: 0.06, 1.72], $Z=2.10[p=0.04])$ There were only trivial differences $(0.04,[95 \% \mathrm{Cl}:-0.36,0.43], Z=0.18[p=0.86])$ between the effects on aerobic endurance performance of SSG and CET. Subgroup analyses showed mostly trivial differences between the training methods across key programming variables such as set duration ( $\geq$ or $<$ than 4 minutes) and recovery period between sets $(\geq$ or $<$ than 3 minutes). Programmes that were longer than 8 weeks favoured SSGs (ES = 0.45 [95\% Cl: $-0.12,1.02], Z=1.54[p=0.12])$, with the opposite being true for CET $(E S=-0.33[95 \% \mathrm{Cl}:-0.79,0.14], Z=1.39[p=0.16]$. Programmes with more than 4 sets per session favoured SSGs $(E S=0.53[95 \% \mathrm{Cl}:-0.52,1.58], Z=0.98[p=0.33])$ with only a trivial difference between those with 4 , or fewer, sets $(E S=-0.13[95 \% \mathrm{Cl}$ : $-0.52,0.26], Z=0.65[p=0.52])$.

Conclusions: SSGs are as effective as CET for increasing aerobic endurance performance in male youth soccer players. This is important for practitioners as it means that SSGs can allow both endurance and skills training to be carried out simultaneously, thus providing a more efficient training stimulus. SSGs offer the same benefits as CET with two sessions per week, with $\geq 4$ sets of 4 minutes of activity, interspersed with recovery periods of 3 minutes, recommended in this population.

Key points:

- Small-sided games are an effective method for the development of endurance in male youth soccer players and can be used to achieve the same performance improvements as conventional endurance training. 
- The use of small-sided games in soccer could maximise skill development at an early age and help to maintain motivation in younger players, whilst also addressing the physiological demands of the sport.

- Small-sided games programmes should comprise of two sessions per week, with 4 or more sets of 4 minutes of activity, interspersed with recovery periods of 3 minutes. 


\section{Introduction}

Soccer is a high-intensity sport of intermittent bouts of activity, which places a substantial demand on the aerobic system [1]. Aerobic energy contributes approximately $90 \%$ of the total energy cost during competitive play [1] and aerobic fitness profiles are strongly related to performance-orientated outcomes $[2,3]$. Conventional endurance training (CET), such as steady state or extensive interval training, has traditionally been part of soccer coaches' aerobic training programmes as it can enhance endurance capabilities [4]. However, despite the effectiveness of this type of training on maximal oxygen uptake $\left(\dot{V}_{2 m a x}\right)$ enhancement, running economy and blood lactate profiles [4], CET does not necessarily mimic the intermittent activity profile of a soccer match and does not require the player to perform relevant soccer skills whilst under fatigue [5]. This is an important element that needs to be addressed by soccer coaches because fatigue has been shown to negatively impact upon skill performance [6], thus necessitating training methods which can improve a player's performance during periods of relatively higher intensity. To this end, small sided games (SSGs [i.e. soccer played on a smaller sized pitch with fewer than the usual 11 players per team]) have been used by coaches to simultaneously target both endurance capacity and technical skill development [5]. This constitutes an efficient training solution which directly addresses the primary demands of soccer play.

Recently, Hammami et al. [7] summarised the effects of SSGs across 16 studies which were drawn from multiple sports and population types. The authors concluded that SSGs were more effective for the development of skill and endurance than traditional conditioning or training. However, due to the diverse nature of the studies included in the meta-analysis (i.e. multiple sports in adults and children of both sexes), the authors 
could not make more focused recommendations based on sport and population type. Because different team sports, such as soccer, rugby and field hockey, place a diverse spectrum of demands on players, it is important for coaches to be able to determine the effectiveness of SSGs in the specific sport within which they operate. Moreover, population-specific recommendations are also important given the differences in adaptations to exercise between adults and youths [5], as well as males and females $[8]$.

There is a large amount of research [9-14] on SSGs in soccer which assess acute responses to exercise in young players and effective game format configurations. This information is often then used as a basis for long-term SSG programme prescription despite the short-term, and cross-sectional, nature of the originally gathered data. Several studies have been carried out and these studies examine a wide variety of different training variables for SSGs such as player numbers [9], pitch size [10], game rules [11] and player behaviour [12] amongst other considerations [13,14]. Though these recommendations are founded upon research that is mostly sound, as yet there has been no quantitative summary on the effects of longer-term SSG interventions, as compared to CET, in youth soccer players. Similarly, there is no statistically-supported consensus on how training variables, such as number of sets, work set duration and recovery period influence adaptations to SSG. These are important factors for coaches to consider when aiming to improve aerobic performance in youth players who may be highly susceptible to overtraining and burnout, which could lead to injury or abstinence from soccer, especially considering the congested tournament configuration in some competitions [15]. Given that SSGs can serve as a time- and skill-efficient solution to meeting the demands of soccer, an investigation into their effects compared to CET in youth soccer players is warranted. Therefore, the main 
purpose of this systematic review and meta-analysis was to compare the effects of SSGs and CET on aerobic endurance performance in male youth soccer players. A secondary aim was to establish clear guidelines for the prescription of SSG training in youth soccer players.

\section{Methods}

This meta-analysis was conducted in accordance with the Preferred Reporting Items for Systematic Reviews and Meta-Analyses (PRISMA) statement [16]. The literature search was performed by $\mathrm{JM}$ and the data extraction and verification was done by JM and JF.

\subsection{Literature search}

With no date restrictions, a systematic search of the Google Scholar, PubMed and Microsoft Academic was undertaken. Only articles published in the English language were considered. These searches were performed in May, 2018. Using Boolean logic, we used the search terms: 'youth' AND 'training' AND 'small sided games' AND 'soccer' OR 'football' OR 'skill' OR 'endurance'. In selecting studies for inclusion, a review of all relevant article titles was conducted before an examination of article abstracts and, then, full published articles. Only peer-reviewed articles were included in the meta-analysis. Following the formal systematic searches, additional handsearches were conducted.

The search process is outlined in Figure 1.

Figure 1 Flow chart for inclusion and exclusion of studies

\subsection{Inclusion and exclusion criteria}


Data were extracted from gathered articles with a form created in Microsoft Excel. The following criteria determined the eligibility of studies for inclusion in the review: studies which applied a SSG programme of 4 weeks or more; cohorts of healthy male soccer players, with a mean age between 8 and 18 years; group mean baseline and followup data outcome measures relating to endurance performance; a comparison group which was engaged in CET. As it can be inherently difficult to ensure a training study meets all of the criteria that determine if it can be considered of high quality [38], we did not stipulate that researchers must have randomised their participants. This also helped to maximise includable data. We defined SSG as "modified [soccer] games played on reduced pitch areas, often using adapted rules and involving a smaller number of players than traditional games" [17]. We defined CET as continuous running or extensive interval training consisting of work durations $>3$ mins [18]. We chose studies with a minimum duration of 4 weeks to account for the potentially slow time course of adaptation to aerobic training in youth $[19,20]$, as well as the unpredictable nature of SSG training which may require a period of habituation over a number of weeks. We included males only because the pooling of performance data of both females and males for analysis within the same studies is not an acceptable practice in research as it only determines whether a training method is effective independent of any population-specific effects. Such an approach would not have considered the effects of sex and maturation level on training status given that boys and girls are biologically different and experience different maturational changes at different times and tempos [8]. The outcome variable of interest was $\dot{V} \mathrm{O}_{2 \max }$, measured directly, or indirectly via field test. This was rationalised on the basis that aerobic metabolism is the primary pathway of energy production in soccer [3] and it can be enhanced in players through the use of small-sided games [20]. If $\dot{V}_{2 \max }$ was unavailable, we were 
satisfied to include studies which assessed endurance performance by way of other measures such as multi-stage fitness tests, basing this on logically defensible rationale. This is an accepted method of study-inclusion justification in meta-analysis [21] and is used elsewhere in the literature on training in youth athletes [8,22]. Observational studies which lacked a clear description of the applied training stimulus were not considered. Similarly, studies which involved any form of dietary manipulation (i.e. supplementation or fasting) were not considered. The characteristics of the study participants and training programmes are displayed in Tables 1 and 2 respectively.

\section{Table 1 Characteristics of study participants}

\section{Table 2 Characteristics of training programmes}

\subsection{Analysis and interpretation of results}

Meta-analytical comparisons were carried out in RevMan version 5.3 [29]. Means and standard deviations for a measure of post-intervention endurance performance were used to calculate an effect size (ES). The inverse-variance random effects model for meta-analyses was used because it allocates a proportionate weight to trials based on the size of their individual standard errors [30] and facilitates analysis whilst accounting for heterogeneity across studies. Effect sizes are represented by the standardised mean difference and are presented alongside $95 \%$ confidence intervals (CI). The calculated ESs were interpreted using the conventions outlined for standardised mean difference by Hopkins et al. [31] $(<0.2=$ trivial; $0.2-0.59=$ small, 0.6-1.19 = moderate, 1.2-1.99 = large, 2.0-3.99 = very large, $>4.0=$ extremely large $)$.

To gauge the degree of heterogeneity amongst the included studies, the $I^{2}$ statistic was referred to. This represents the proportion of effects that are due to heterogeneity as opposed to chance [16]. Low, moderate and high levels of heterogeneity 
correspond to $I^{2}$ values of $25 \%, 50 \%$ and $75 \%$ respectively; however, these thresholds are considered tentative [32]. The $X^{2}$ (chi square) assesses if any observed differences in results are compatible with chance alone. A low $\mathrm{P}$ value, or a large chi-squared statistic relative to its degree of freedom, provides evidence of heterogeneity of intervention effects beyond those attributed to chance [30].

\subsection{Assessment of risk of bias}

The Physiotherapy Evidence Database (PEDro) scale was used to assess the risk of bias and methodological quality of eligible studies included in the meta-analysis. This scale evaluates internal study validity on a scale from 0 (high risk of bias) to 10 (low risk of bias). A score of $\geq 6$ represents the threshold for studies with low risk of bias [33]. The articles were assessed by JM and $\mathrm{HC}$ and the agreed upon ratings are presented in Table 3. For the assessment of publication bias, a funnel plot is presented in Figure 2.

\section{Table 3 PEDro scale}

\section{Figure 2 Funnel plot}

\subsection{Analysis of moderator variables}

To assess the potential effects of moderator variables, subgroup analyses were performed. This method was preferred to meta-regression based on documented limitations of the latter method when applied to small datasets with low sample sizes and few predictor variables [34].

Using a random effects model, we selected potential moderators likely to influence the effects of training. Participants were divided using a median split for the following variables: age $(\geq 15.7 \mathrm{yrs})$, height $(\geq 174.0 \mathrm{~cm})$, body mass $(\leq 62.1 \mathrm{~kg})$, total number of 
training sessions $(\geq 16)$, mean number of sets per session $(>4)$, mean set duration $(\geq 4$ minutes) and mean recovery time between sets ( $\geq 3$ minutes). Studies included in the programme duration subgroup ( $\geq 8$ weeks) were divided on the basis that in previous work, neither maximal nor submaximal aerobic training variables were altered after 8 weeks of either sprint interval or continuous training in young boys [19]. Training frequency per week was divided into the following subgroups: 2 sessions or $>2$ sessions per week, as these were the only possible classifications to make with the available data. For the calculation of effect sizes based on programming parameters, mean values for variables, such as set time, were used where necessary.

\section{Results}

\subsection{Main effect}

Seven studies were included in this meta-analysis. There was a trivial between-mode ES $(0.04[95 \% \mathrm{Cl}:-0.36,0.43], Z=0.18[p=0.86])$ in endurance performance which was not significant. The mean score of the included studies relating to risk of bias was 5.3. There was a non-significant level of between-study heterogeneity $\left(I^{2}=27 \%[p=\right.$ 0.22]). Within-mode ESs were both of moderate magnitude (SSG: 0.82 [95\% Cl: 0.05 , 1.60], $Z=2.07$ [p = 0.04]; CET: 0.89 [95\% Cl: 0.06, 1.72], $Z=2.10[p=0.04])$. These results are displayed in Figure 3 (SSG [a] vs. CET [b]) and Figure 4 (baseline vs. follow-up).

Figure 3 Forest plot of between-mode effect sizes with $95 \%$ confidence intervals

Figure 4 Forest plot of within-mode effect sizes with $95 \%$ confidence intervals

\subsection{Effect of moderator variables}


Subgroup analysis, shown in Table 4, showed between-group heterogeneity ranging from low to high, demonstrating statistical significance in one case (number of weeks $[p=0.04])$. Differences were trivial to small between each training type across subgroups. Programmes that were longer than 8 weeks had larger effect sizes in SSG $(E S=0.45[-0.12,1.02], Z=1.54[p=0.12])$, with the opposite being true for CET (ES $=-0.33[95 \% \mathrm{Cl}:-0.79,0.14], Z=1.39[p=0.16]$. Programmes with more than 4 sets per session favoured SSGs (ES $=0.53[95 \% \mathrm{Cl}:-0.52,1.58], Z=0.98[p=0.33])$ with only a trivial difference between those with 4 , or fewer, sets $(E S=-0.13[95 \% \mathrm{Cl}$ : $0.52,0.26], Z=0.65[p=0.52])$.

\section{Table 4 Subgroup analyses}

\section{Discussion}

The main findings of this meta-analysis indicate that SSGs can be used instead of, or in addition to, CET to target endurance performance in male youth soccer players. This has important implications for coaches because it means that male youth soccer players can develop endurance qualities and technical skills concurrently, thus representing a more time-efficient approach to training [35]. This is favourable in comparison to the relatively one-dimensional nature of CET, which permits only the targeting of endurance performance. On that basis, overuse of CET could also add to a congested training schedule causing excessive physical stress which, in turn, can result in burnout and/or injury in youth players [36]. In addition, it is reported that CET is less enjoyable to youth soccer players compared to other training formats [37]. Previous evidence indicates that youth soccer players experience negative outcomes relating to physical performance [38] and hormonal profile [39] during periods of higher density training [15], which necessitates the careful balancing of workloads in the 
younger individual. SSGs can facilitate this balance by providing a multidimensional approach to addressing the diverse demands of soccer play [14]. However, coaches must be aware that with the use of SSGs comes increased chances of sustaining contact-based injuries. In this way, CET can serve a purpose for players who are returning to play or who are in need of a volume of non-contact training time.

Whilst the within- and between-mode analyses both reveal SSG training and CET to be equally effective in enhancing endurance performance in male youth soccer players, some of the effect sizes seen in individual studies warrant further investigation. Jastrzebski et al. [25] found that SSGs exerted a moderate effect on performance whilst CET resulted only in a borderline trivial-small effect size. The authors reported that both groups experienced similar changes in $\dot{V}_{2 \max }$ but inspection of the effect sizes in our meta-analyses suggests that this was not the case (0.82 [SSG] vs. 0.21 [CET]). Jastrzebski et al. [25] allude to performance increases due to SSG being related to the competitive nature of that type of activity, with this feature not necessarily being as important in CET. It is worth noting that previous evidence indicates that despite training heart rate responses being similar in both SSGs and CET, the latter training type seems to induce perceptions of higher intensity in players [24]. It is possible that this is an important factor in adaptations to SSGs with lower perception of effort potentially resulting in a greater level of engagement with the training process. We tentatively suggest that neither players or coaches would be as motivated to increase intensity in this way when undertaking CET only. In contrast to the findings of Jastrzebski et al. [25], Eniseler et al. [23], found larger effects with CET than they did in SSGs. The researchers speculated on a number of different potential explanations on the discrepancy in performances between the groups, the most compelling of which relates to the motivation of athletes to take full part in training. 
Though it seems that SSG training is preferable to CET from an enjoyment perspective [37], this does not necessarily guard against players taking voluntary rest periods during the course of the activity. Unlike CET, SSGs are inherently acyclic and unpredictable in format meaning coaches must make extra efforts to keep players consistently involved in play. Reinforcing this is the previous finding that verbal encouragement seems to exert a clear and direct effect on the intensity of SSGs [40], underlining coaches' ability to influence player activity as, and when, required.

Subgroup analyses revealed similar findings to the main analysis with few differences observed for the effects of training when study cohorts were divided by age, stature or body mass. These findings are important in light of previous indications of a maturational threshold that moderates responses to training in youth, suggesting that less mature individuals may not adapt to the imposed demands of endurance exercise [41]. Albeit based on limited data and proxies (age, stature, body mass) of maturational status only, the current results indicate that SSGs are a favourable alternative to CET regardless of age or maturation status meaning that coaches can effectively utilise the method across the maturational spectrum.

Further subgroup analyses of programming parameters also revealed some interesting findings. Interventions with more than 4 sets per session favoured SSGs. This would seem to indicate that SSG session volume and, by extension, overall training volume is an important factor in programming this type of exercise in youth soccer players. This result is reinforced by the finding that a higher overall load of sessions ( $\geq 16)$ favoured SSGs. Training volume is thought to be a key determinant of mitochondrial content, one of the primary adaptive responses to aerobic training [42]. This suggests coaches should place a high level of importance on this programming variable to ensure larger adaptations. However, it is vital that coaches temper their 
use of higher training volumes to avoid overtraining and overuse injury. Coaches should therefore prescribe an appropriate balance of work and recovery to ensure players can recuperate from the rigours of SSGs. On this point, training frequencies of more than 2 per week do not seem to favour SSGs, possibly due to the greater number of high-intensity movements, in comparison to CET, that have been reported in youth soccer [43]. Accordingly, SSGs, as used for the purposes of enhancing endurance performance, can be programmed up to two times per week with adequate recovery between bouts of activity. However, owing to the homogeneity of training frequencies used across studies, more research, utilising varying amounts of sessions per week, must be carried out to establish more robust recommendations for this parameter. Researchers are therefore encouraged to carry out studies examining the effects of 1, 3, 4 or more SSG sessions per week in youth soccer players.

A further finding of subgroup analyses is related to the duration of the SSG and CET programmes that were used in the included studies. Programmes which lasted 8 weeks or more seemed to favour SSG training whilst programmes carried out for a shorter period of time favoured CET. Based on these findings, coaches may have to expose youth players to longer SSGs training interventions to elicit a comparable training response, possibly due to the unpredictable player movement profiles associated with this type of activity. For example, it is possible that, as in traditional soccer play, players could self-regulate their activity levels during SSG training, increasing or decreasing their effort depending on the nature of the game itself and the unpredictability of in-play events. Increases in performance could therefore manifest quicker with the more focused approach of CET, but this method has the disadvantage that it does not necessarily support the development of technical soccer skills. This seems a plausible explanation for this result. Previous work which 
compared physiological responses to SSGs and CET in youth soccer players indicated differences across a number of endurance-related variables. Ade et al. [43] reported that speed endurance running drills induced higher heart-rate responses, blood lactate concentrations, and ratings of perceived exertion than similarly configured SSGs. Moreover, total distance covered and high intensity running distance was greater in running drills than in SSGs with the latter seemingly more effective in stimulating development of the anaerobic energy system. If this was the case in the studies included in the current analyses, it could be that it takes a longer period of time for SSGs to adequately stimulate the underpinning factors that determine endurance performance in youth soccer players. Related to this point, training intensity is difficult to control within SSGs but perhaps, given the similarity of adaptation to CET, does not need to be tightly controlled by coaches if training is carried out for an appropriate amount of time. As training volume (duration) was equated in the studies included in this meta-analysis, the findings suggest that intensity was also similar between the CET and SSG conditions, most particularly in relation to the main effect. Any other differences between SSGs and CET could be reflected by the type of endurance test used to measure the effects of the training intervention. For example, the greater the level of equivalence between the training method and the endurance test used, the more likely that test might be to reflect any changes in performance.

There are a number of limitations associated with this meta-analysis. The high number of moderator variables chosen can falsely increase the chances of positive findings [44], though these factors were determined a priori and are highly relevant to the analyses undertaken. Regardless, these recommendations must be viewed with caution as the dichotomisation of continuous data with median split could result in residual confounding and reduced statistical power $[45,46]$. This is further underlined 
by the low number of studies that qualified for this meta-analysis but the results can, nonetheless, be used to form a consensus on the effectiveness of SSGs for youth athletic development. Furthermore, few studies have reported performance measures (i.e. global positioning system data, fatigue index), and external validity is thus generally quite low. Future studies can further establish the variables that are of most importance for enhancing aerobic endurance performance in youth soccer players, whilst inter-individual responses [47] to SSG and CET should also be investigated. This supports a more focused approach to programming for endurance training whereby an individual can be exposed to the modality to which they respond best (i.e. SSGs vs. CET). It also remains unclear whether or not a combination of SSGs and CET would be a more effective training stimulus. Though the current data do not support it, as youth soccer players become fitter, they may need to be exposed to alternative or hybrid training modalities to continue to drive adaptations.

\section{Conclusion}

The findings of this meta-analysis suggest that SSGs can be used instead of, or in addition to, CET for the development of endurance in male youth soccer players. Indeed, it seems that CET may not be expressly required in youth because the same performance improvements can be achieved via use of SSGs. This finding is further strengthened by other evidence which suggests SSGs can simultaneously target technical skill development, making it a more attractive training option than CET. If fitness qualities can be developed and maintained in a way that keeps the individual engaged and exposes them to a wide variety of movement patterns and technical skills, several long term athletic development goals can be targeted concurrently. This can increase athlete engagement whilst also reducing overall workloads due to enhanced training efficiency. Training programmes should be carried out for an 
extended period of time (>8 weeks) and should include 4 or more sets per session, 4 minutes per set and 3 minutes recovery between sets [48]. These training variables are in line with seminal recommendations for aerobic training in young soccer players [48] and are congruent with the results of our analyses. Despite this, our results are based on small sample sizes and more studies should be carried out to verify these recommendations.

\section{Compliance with Ethical Standards}

Funding

No sources of funding were used to assist in the preparation of this article.

Conflicts of Interest

Jason Moran, Richard C. Blagrove, Benjamin Drury, John F.T. Fernandes, Kevin Paxton, Helmi Chaabene and Rodrigo Ramirez-Campillo declare that they have no conflicts of interest relevant to the content of this review.

\section{References}

1. Bangsbo J. The physiology of soccer--with special reference to intense intermittent exercise. Acta Physiol Scand Suppl. 1994;619:1-155.

2. Chamari K, Hachana Y, Kaouech F, Jeddi R, Moussa-Chamari I, Wisloff U. Endurance training and testing with the ball in young elite soccer players. Br J Sports Med. 2005;39:24-8.

3. McMillan K, Helgerud J, Macdonald R, Hoff J. Physiological adaptations to soccer specific endurance training in professional youth soccer players. Br J Sports Med. 2005;39:273-7. 
4. laia MF, Rampinini E, Bangsbo J. High-intensity training in football. Int J Sports Physiol Perform. 2009;4:291-306.

5. Harrison CB, Gill ND, Kinugasa T, Kilding AE. Development of aerobic fitness in young team sport athletes. Sports Med. 2015;45:969-83.

6. Russell M, Kingsley M. Influence of exercise on skill proficiency in soccer. Sports Med. 2011;41:523-39.

7. Hammami A, Gabbett TJ, Slimani M, Bouhlel E. Does small-sided games training improve physical-fitness and specific skills for team sports? A systematic review with meta-analysis. J Sports Med Phys Fitness. 2017;1-25.

8. Moran J, Sandercock G, Ramirez-Campillo R, Clark C, Fernandes J, Drury B. A meta-analysis of resistance training in female youth: its effect on muscular strength, and shortcomings in the literature. Sports Med. 2018;48:1661-71.

9. Castellano J, Casamichana D, Dellal A. Influence of game format and number of players on heart rate responses and physical demands in small-sided soccer games. J Strength Cond Res. 2013;27:1295-303.

10. Casamichana D, Castellano J. Time-motion, heart rate, perceptual and motor behaviour demands in small-sides soccer games: Effects of pitch size. J Sports Sci. 2010;28:1615-23.

11. Hill-Haas SV, Coutts AJ, Dawson BT, Rowsell GJ. Time-motion characteristics and physiological responses of small-sided games in elite youth players: The influence of player number and rule changes. J Strength Cond Res. 2010;24:2149_ 56.

12. Ngo JK, Tsui MC, Smith AW, Carling C, Chan GS, Wong DP. The effects of 
man-marking on work intensity in small-sided soccer games. J Sport Sci Med. 2012;11:109-14.

13. Sanchez-Sanchez J, Ramirez-Campillo R, Carretero M, Martín V, Hernández D, Nakamura FY. Soccer small-sided games activities vary according to the interval regime and their order of presentation within the session. J Hum Kinet. 2018;62:16775.

14. Sanchez-Sanchez J, Hernández D, Casamichana D, Martínez-Salazar C, Ramirez-Campillo R, Sampaio J. Heart rate, technical performance, and session-rpe in elite youth soccer small-sided games played with wildcard players. J Strength Cond Res. 2017;31:2678-85.

15. Sanchez-Sanchez J, Sanchez M, Hernandez D, Ramirez-Campillo R, Martínez C, Nakamura FY. Fatigue in u12 soccer-7 players during repeated one-day tournament games - a pilot study. J Strength Cond Res. 2017; In Press.

16. Liberati A, Altman DG, Tetzlaff J, Mulrow C, Gøtzsche PC, loannidis JPAA, et al. The PRISMA statement for reporting systematic reviews and meta-analyses of studies that evaluate health care interventions: explanation and elaboration. J Clin Epidemiol. 2009;62:e1-34.

17. Hill-Haas SV, Dawson B, Impellizzeri FM, Coutts AJ. Physiology of small-sided games training in football: A systematic review. Sports Med. 2011;41:199-220.

18. Kibler W Ben, Allistratos ELK, Afis GIKP, Atsikas CHAK, Ouvis STD, Frost DM, et al. Interval training for performance: a scientific and empirical practice. Sports Med. 2014;38:1-3.

19. Williams CA, Armstrong N, Powell J. Aerobic responses of prepubertal boys to 
two modes of training. Br J Sports Med. 2000;34:168-73.

20. Impellizzeri FM, Marcora SM, Castagna C, Reilly T, Sassi A, laia FM, et al. Physiological and performance effects of generic versus specific aerobic training in soccer players. Int J Sports Med. 2006;27:483-92.

21. Turner HM, Bernard RM. Calculating and synthesizing effect sizes. Contemp Issues Commun Sci Disord. 2006;33:42-55.

22. Moran J, Sandercock GRH, Ramírez-Campillo R, Meylan C, Collison J, Parry DA. A meta-analysis of maturation-related variation in adolescent boy athletes' adaptations to short-term resistance training. J Sports Sci. 2017;35:1041-51.

23. Eniseler N, Şahan Ç, Özcan I, Dinler K. High-intensity small-sided games versus repeated sprint training in junior soccer players. J Hum Kinet. 2017;60:101-11.

24. Hill-Haas SV, Coutts AJ, Rowsell GJ, Dawson BT. Generic versus small-sided game training in soccer. Int J Sports Med. 2009;30:636-42.

25. Jastrzebski Z, Barnat W, Dargiewicz R, Jaskulska E, Szwarc A, Radzimiński Ł. Effect of in-season generic and soccer-specific high-intensity interval training in young soccer players. Int J Sports Sci Coach. 2014;9:1169-79.

26. Los Arcos A, Vázquez JS, Martin J, Lerga J, Sánchez F, Villagra F, et al. Effects of small-sided games vs. interval training in aerobic fitness and physical enjoyment in young elite soccer players. PLoS One. 2015;10.

27. Radziminski L, Rompa P, Barnat W, Dargiewicz R, Jastrzebski Z. A comparison of the physiological and technical effects of high-intensity running and small-sided games in young soccer players. Int J Sports Sci Coach. 2013;8:455-66.

28. Safania AM, Alizadeh R, Nourshahi M, Branch AA. A comparison of small-side 
games and interval training on same selected physical fitness factors in amateur soccer players. Soc Sci. 2011;7:349-53.

29. The Nordic Cochrane Centre. Review Manager. Cochrane Collab. 2014. p. 1-43.

30. Deeks JJ, Higgins JP, Altman DG. Analysing data and undertaking metaanalyses. Cochrane Handb Syst Rev Interv Cochrane B Ser. 2008. p. 243-96.

31. Hopkins WG, Marshall SW, Batterham AM, Hanin J. Progressive statistics for studies in sports medicine and exercise science. Med Sci Sports Exerc. 2009;41:312.

32. Higgins JPT, Thompson SG, Deeks JJ, Altman DG. Measuring inconsistency in meta-analyses. BMJ. 2003;327:557-60.

33. Maher CG, Sherrington C, Herbert RD, Moseley AM, Elkins M. Reliability of the PEDro scale for rating quality of randomized controlled trials. Phys Ther. 2003;83:713-21.

34. Schmidt FL. Statistical and measurement pitfalls in the use of meta-regression in meta-analysis. Career Dev Int. 2017;22:469-76.

35. Harrison CB, Kinugasa T, Gill N, Kilding AE. Aerobic fitness for young athletes: combining game-based and high-intensity interval training. Int J Sports Med. 2015;36:929-34.

36. Brink MS, Visscher C, Arends S, Zwerver J, Post WJ, Lemmink KAPM. Monitoring stress and recovery: New insights for the prevention of injuries and illnesses in elite youth soccer players. Br J Sports Med. 2010;44:809-15.

37. Ward P, Hodges NJ, Starkes JL, Williams MA. The road to excellence: Deliberate practice and the development of expertise. High Abil Stud. 2007;18:119- 
53.

38. Arruda AFS, Carling C, Zanetti V, Aoki MS, Coutts AJ, Moreira A. Effects of a very congested match schedule on body-load impacts, accelerations, and running measures in youth soccer players. Int J Sports Physiol Perform. 2015;10:248-52.

39. Moreira A, Bradley P, Carling C, Arruda AFS, Spigolon LMP, Franciscon C, et al. Effect of a congested match schedule on immune-endocrine responses, technical performance and session-RPE in elite youth soccer players. J Sports Sci. 2016;34:2255-61.

40. Rampinini E, Impellizzeri FM, Castagna C, Abt G, Chamari K, Sassi A, et al. Factors influencing physiological responses to small-sided soccer games. J Sports Sci. 2007;25:659-66.

41. Armstrong N, McNarry M. Aerobic fitness and trainability in healthy youth: gaps in our knowledge. Pediatr Exerc Sci. 2016;28:171-7.

42. Bishop DJ, Granata C, Eynon N. Can we optimise the exercise training prescription to maximise improvements in mitochondria function and content? Biochim Biophys Acta - Gen Subj. 2014;1840:1266-75.

43. Ade JD, Harley JA, Bradley PS. Physiological response, time-motion characteristics, and reproducibility of various speed-endurance drills in elite youth soccer players: Small-sided games versus generic running. Int J Sports Physiol Perform. 2014;9:471-9.

44. Burke JF, Sussman JB, Kent DM, Hayward RA. Three simple rules to ensure reasonably credible subgroup analyses. BMJ. 2015;351.

45. Altman DG, Royston P. The cost of dichotomising continuous variables. BMJ. 
2006;332:1080.

46. Sandercock GRH, Bromley PD, Brodie DA. Effects of exercise on heart rate variability: inferences from meta-analysis. Med Sci Sports Exerc. 2005;37:433-9.

47. Bonafiglia JT, Rotundo MP, Whittall JP, Scribbans TD, Graham RB, Gurd BJ. Inter-individual variability in the adaptive responses to endurance and sprint interval training: A randomized crossover study. PLoS One. 2016;11.

48. Helgerud J, Engen LC, Wisloff U, Hoff J, Wisløff U, Hoff J. Aerobic endurance training improves soccer performance. Med Sci Sports Exerc. 2001;33:1925-31. 


\section{Figure 1 Flow chart for inclusion and exclusion of studies}

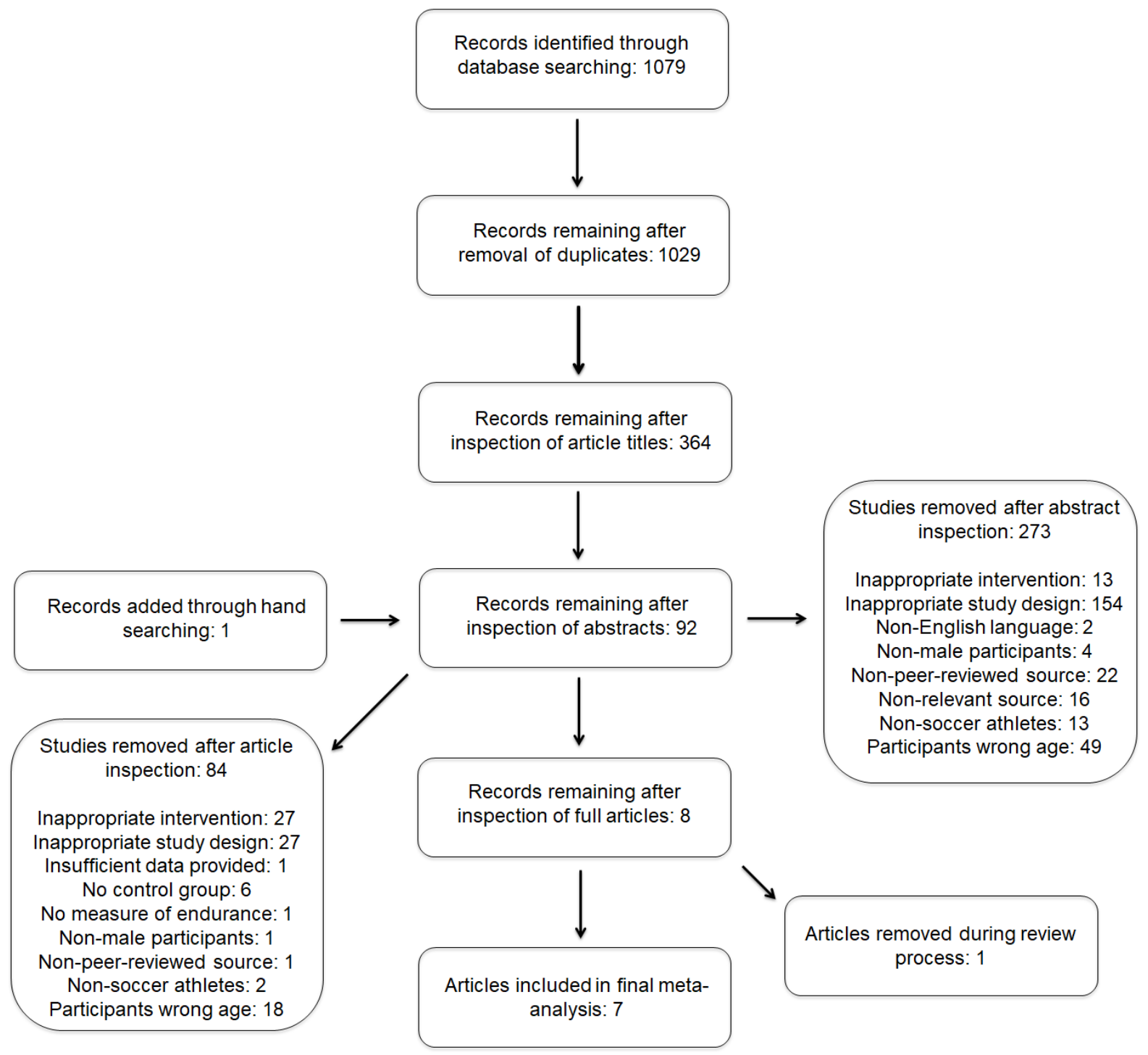




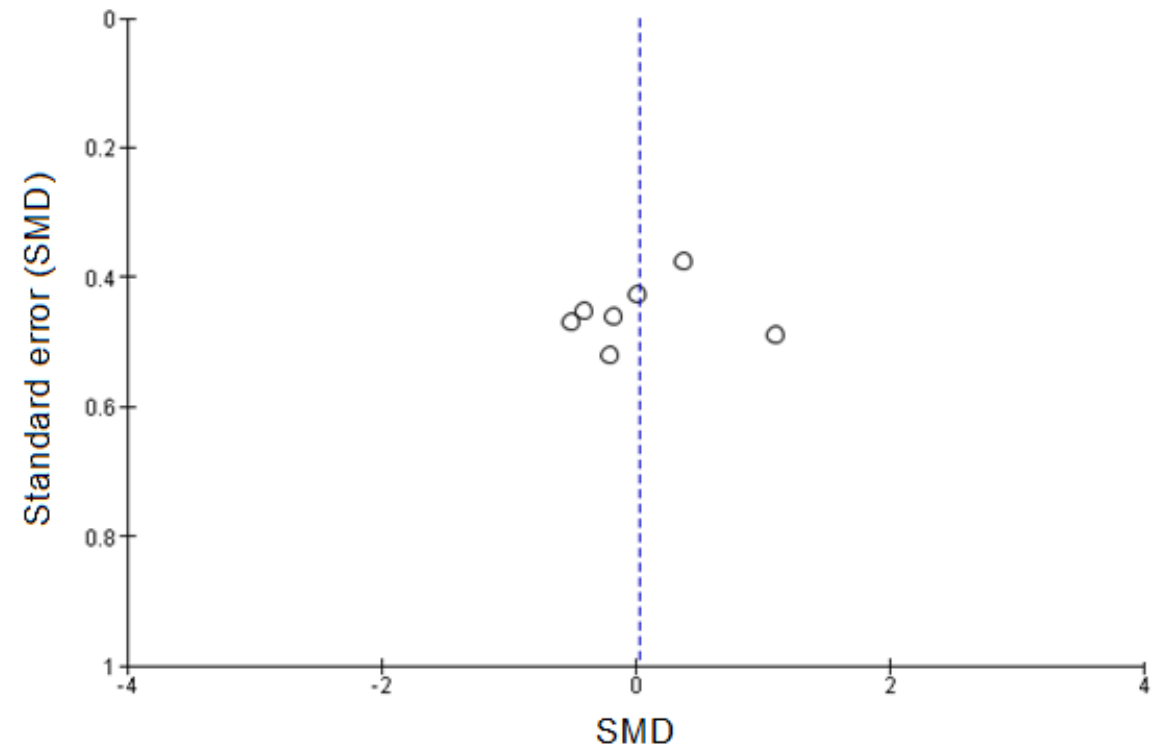

Figure 2 Funnel plot

Fig. 2 Funnel plot of publication bias. SMD = standardized mean difference 


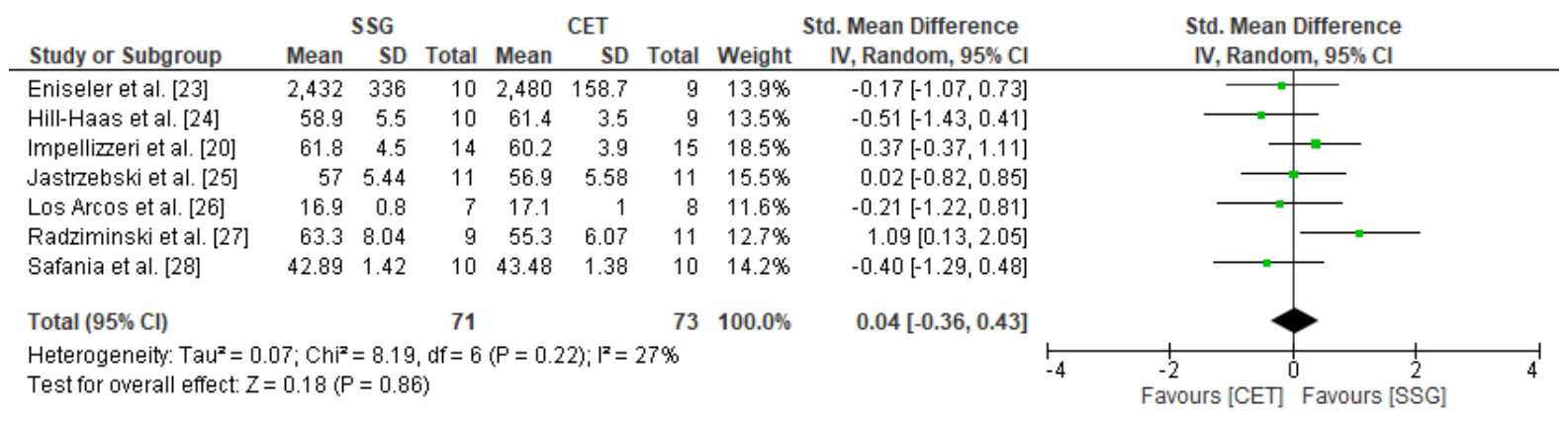

Figure 3 Forest plot of between-mode effect sizes with $95 \%$ confidence

intervals

Legend - Std = standardised; IV = inverse variance method; $\mathrm{CI}=$ confidence interval; $\mathrm{SSG}=$ small sided games; $\mathrm{CET}=$ conventional endurance training 


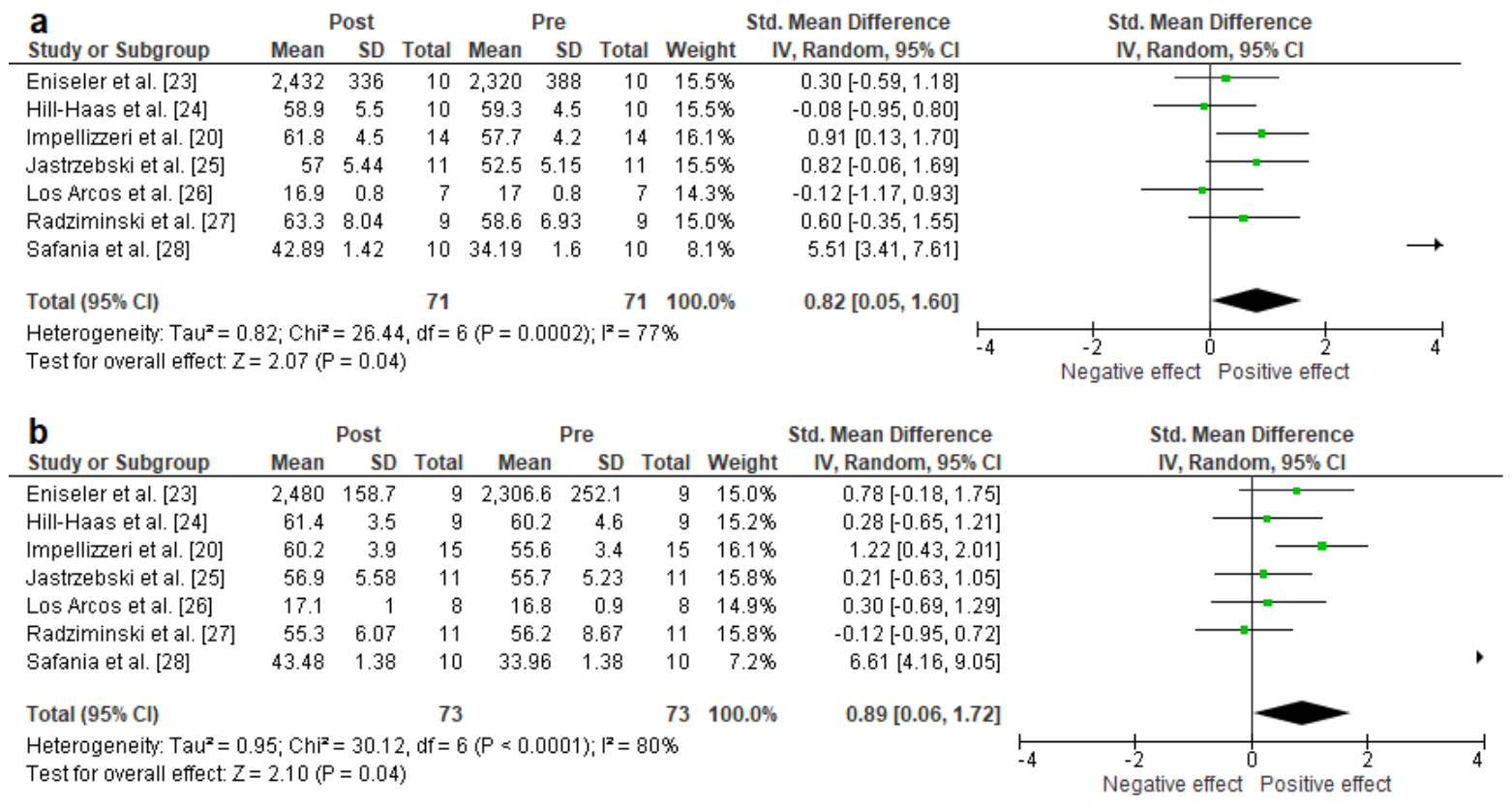

Figure 4 Forest plot of within-mode effect sizes with $95 \%$ confidence intervals

a: SSG = small sided games; $b$ : CET = conventional endurance training

Legend $-\mathrm{STD}=$ standardised; IV = inverse variance method; $\mathrm{Cl}$ = confidence interval 
Table 1 Characteristics of study participants

\begin{tabular}{|c|c|c|c|c|c|}
\hline Study & Study group & $\begin{array}{l}\text { Participants } \\
\text { (n) }\end{array}$ & Age (SD) (yrs) & Height (SD) (cm) & Body mass (SD) (kg) \\
\hline Eniseler et al. [23] & $\begin{array}{l}\text { Small-sided games } \\
\text { Repeated-sprint training }\end{array}$ & $\begin{array}{l}10 \\
9\end{array}$ & $\begin{array}{l}17.07(1.22) \\
16.84(1.18)\end{array}$ & $\begin{array}{l}174.0(3.26) \\
172.0(4.82)\end{array}$ & $\begin{array}{l}65.8(5.9) \\
65.4(5.2)\end{array}$ \\
\hline Hill-Haas et al. [24] & $\begin{array}{l}\text { Small-sided games } \\
\text { Generic training }\end{array}$ & $\begin{array}{l}10 \\
9\end{array}$ & $\begin{array}{l}14.6(0.9) \\
14.6(0.9)\end{array}$ & $\begin{array}{l}172.0(5.8) \\
172.0(5.8)\end{array}$ & $\begin{array}{l}62.1(6.2) \\
62.1(6.2)\end{array}$ \\
\hline Impellizzeri et al. [20] & $\begin{array}{l}\text { Specific training group } \\
\text { Generic training group }\end{array}$ & $\begin{array}{l}14 \\
15\end{array}$ & $\begin{array}{l}17.2(0.8) \\
17.2(0.8)\end{array}$ & $\begin{array}{l}178.1(5.8) \\
178.1(5.8)\end{array}$ & $\begin{array}{l}69.1(4.7) \\
69.1(4.7)\end{array}$ \\
\hline Jastrzebski et al. [25] & $\begin{array}{l}\text { Small-sided games group } \\
\text { Interval-running group }\end{array}$ & $\begin{array}{l}11 \\
11\end{array}$ & $\begin{array}{l}15.8(0.63) \\
15.8(0.55)\end{array}$ & $\begin{array}{l}175.0(6.23) \\
177.6(6.48)\end{array}$ & $\begin{array}{l}61.6(8.97) \\
62.7(8.69)\end{array}$ \\
\hline Los Arcos et al. [26] & $\begin{array}{l}\text { Small-sided games } \\
\text { Interval training }\end{array}$ & $\begin{array}{l}7 \\
8\end{array}$ & $\begin{array}{l}15.1(0.7) \\
15.8(0.5)\end{array}$ & $\begin{array}{l}176.0(6.0) \\
177.0(5.0)\end{array}$ & $\begin{array}{l}67.0(5.0) \\
69.0(6.0)\end{array}$ \\
\hline Radziminski et al. [27] & $\begin{array}{l}\text { Small-sided game group } \\
\text { Running group }\end{array}$ & $\begin{array}{l}9 \\
11\end{array}$ & $\begin{array}{l}15.0(0.46) \\
15.1(0.67)\end{array}$ & $\begin{array}{l}172.1(6.55) \\
171.9(5.35)\end{array}$ & $\begin{array}{l}55.3(7.92) \\
57.2(9.11)\end{array}$ \\
\hline Safania et al. [28] & $\begin{array}{l}\text { Small-sided games training } \\
\text { Interval training }\end{array}$ & $\begin{array}{l}10 \\
10\end{array}$ & $\begin{array}{l}15.7(0.7) \\
15.7(0.7)\end{array}$ & $\begin{array}{l}165.34(4.75) \\
165.34(4.75)\end{array}$ & $\begin{array}{l}58.5(5.22) \\
58.5(5.22)\end{array}$ \\
\hline
\end{tabular}


Table 2 Characteristics of training programmes

\begin{tabular}{|c|c|c|c|c|c|c|c|c|c|c|c|c|c|c|c|}
\hline Study & $\begin{array}{l}\text { Study } \\
\text { group }\end{array}$ & Weeks & $\begin{array}{l}\text { Mean } \\
\text { frequency } \\
\text { (per } \\
\text { week) }\end{array}$ & $\begin{array}{l}\text { Total } \\
\text { sessions }\end{array}$ & $\begin{array}{l}\text { Small } \\
\text { sided } \\
\text { games } \\
\text { type }\end{array}$ & $\begin{array}{l}\text { No } \\
\text { of } \\
\text { sets }\end{array}$ & $\begin{array}{l}\text { Set } \\
\text { duration } \\
\text { (mins) }\end{array}$ & $\begin{array}{l}\text { Rest } \\
\text { period } \\
\text { (mins) }\end{array}$ & $\begin{array}{l}\text { No of } \\
\text { players } \\
\text { per } \\
\text { team }\end{array}$ & $\begin{array}{l}\text { Pitch } \\
\text { length } \\
\text { (m) }\end{array}$ & $\begin{array}{l}\text { Pitch } \\
\text { width } \\
\text { (m) }\end{array}$ & $\begin{array}{l}\text { Total } \\
\text { dimensions } \\
\text { (m2) }\end{array}$ & Goalkeepers & $\begin{array}{l}\text { Exercise } \\
\text { intensity }\end{array}$ & Test \\
\hline \multirow[t]{2}{*}{$\begin{array}{l}\text { Eniseler et al. } \\
\text { [23] }\end{array}$} & $\begin{array}{l}\text { Small- } \\
\text { sided } \\
\text { games }\end{array}$ & 6 & 2 & 12 & \multirow[t]{2}{*}{3 vs. 3} & \multirow[t]{2}{*}{4} & \multirow[t]{2}{*}{3} & \multirow[t]{2}{*}{4} & \multirow[t]{2}{*}{3} & \multirow[t]{2}{*}{18} & \multirow[t]{2}{*}{30} & & \multirow[t]{2}{*}{ No } & $\begin{array}{l}90-95 \% \\
\text { HR max }\end{array}$ & \multirow{2}{*}{$\begin{array}{l}\text { Yo-Yo } \\
\text { Intermittent } \\
\text { Recovery } \\
\text { Test Level } \\
1(\mathrm{~m}) \\
\text { Yo-Yo } \\
\text { Intermittent } \\
\text { Recovery } \\
\text { Test Level } \\
1 \mathrm{~m})\end{array}$} \\
\hline & $\begin{array}{l}\text { Repeated- } \\
\text { sprint } \\
\text { training }\end{array}$ & 6 & 2 & 12 & & & & & & & & & & $\begin{array}{l}90-95 \% \\
\text { HR max }\end{array}$ & \\
\hline \multirow[t]{2}{*}{$\begin{array}{l}\text { Hill-Haas et } \\
\text { al. [24] }\end{array}$} & $\begin{array}{l}\text { Small- } \\
\text { sided } \\
\text { games }\end{array}$ & 7 & 2 & 14 & \multirow[t]{2}{*}{$\begin{array}{l}2 \text { vs. } 2 \text { up } \\
\text { to } 7 \text { vs. } 7 \\
\text { under } \\
\text { various } \\
\text { conditions }\end{array}$} & \multirow[t]{2}{*}{$3-6^{a}$} & \multirow[t]{2}{*}{$7-13$} & \multirow[t]{2}{*}{$1-3$} & \multirow[t]{2}{*}{$2-7$} & \multirow[t]{2}{*}{$20-60$} & \multirow[t]{2}{*}{$15-40$} & & \multirow[t]{2}{*}{ No } & $\begin{array}{l}<80 \% \\
\text { HR max } \\
\text { to }>90 \% \\
\text { HR max }\end{array}$ & $\begin{array}{l}\text { Yo-Yo } \\
\text { Intermittent } \\
\text { Recovery } \\
\text { Test Level } \\
1(\text { Vo2 max } \\
{[(\mathrm{ml} \mathrm{kg}-1} \\
\text { min-1]) }\end{array}$ \\
\hline & $\begin{array}{l}\text { Generic } \\
\text { training }\end{array}$ & 7 & 2 & 14 & & & & & & & & & & $\begin{array}{l}<80 \% \\
\text { HR max } \\
\text { to }>90 \% \\
\text { HR max }\end{array}$ & $\begin{array}{l}\text { Yo-Yo } \\
\text { Intermittent } \\
\text { Recovery } \\
\text { Test Level } \\
1(\text { Vo2 max } \\
{[(\mathrm{ml} \mathrm{kg}-1} \\
\text { min-1]) }\end{array}$ \\
\hline \multirow[t]{2}{*}{$\begin{array}{l}\text { Impellizzeri et } \\
\text { al. [20] }\end{array}$} & $\begin{array}{l}\text { Specific } \\
\text { training } \\
\text { group }\end{array}$ & 12 & 2 & 24 & \multirow[t]{2}{*}{$\begin{array}{l}3 \text { vs. } 3,4 \\
\text { vs. } 4,5 \text { vs. } \\
5\end{array}$} & 4 & 4 & 3 & \multirow[t]{2}{*}{$3-5$} & \multirow[t]{2}{*}{$25-40$} & \multirow[t]{2}{*}{$35-50$} & & Yes and no & $\begin{array}{l}90-95 \% \\
\text { HR max }\end{array}$ & \multirow{2}{*}{$\begin{array}{l}\text { Incrementa } \\
\text { treadmill } \\
(\mathrm{ml} \mathrm{kg}-1 \\
\text { min-1) } \\
\text { Incrementa } \\
\text { treadmill } \\
(\mathrm{ml} \mathrm{kg}-1 \\
\text { min-1) }\end{array}$} \\
\hline & $\begin{array}{l}\text { Generic } \\
\text { training } \\
\text { group }\end{array}$ & 12 & 2 & 24 & & 4 & 4 & 3 & & & & & & $\begin{array}{l}90-95 \% \\
\text { HR max }\end{array}$ & \\
\hline \multirow[t]{2}{*}{$\begin{array}{l}\text { Jastrzebski et } \\
\text { al. [25] }\end{array}$} & $\begin{array}{l}\text { Small- } \\
\text { sided } \\
\text { games } \\
\text { group }\end{array}$ & 8 & 2 & 16 & \multirow[t]{2}{*}{$\begin{array}{l}3 \text { vs. } 3 \\
\text { small- } \\
\text { sided } \\
\text { games }\end{array}$} & 7 & 3 & 1.5 & \multirow[t]{2}{*}{3} & \multirow[t]{2}{*}{30} & \multirow[t]{2}{*}{18} & 540 & \multirow[t]{2}{*}{ No } & $\begin{array}{l}\text {-89.5- } \\
90.5 \% \\
\text { HR max }\end{array}$ & $\begin{array}{l}\text { Graded } \\
\text { cycle test } \\
\text { (Vo2 max } \\
{[(\mathrm{ml} \mathrm{kg}-1} \\
\text { min-1]) }\end{array}$ \\
\hline & $\begin{array}{l}\text { Interval- } \\
\text { running } \\
\text { group }\end{array}$ & 8 & 2 & 16 & & 7 & 3 & 1.5 & & & & & & $\begin{array}{l}\sim 88.5- \\
89.5 \% \\
\text { HR max }\end{array}$ & $\begin{array}{l}\text { Graded } \\
\text { cycle test } \\
\text { (Vo2 max }\end{array}$ \\
\hline
\end{tabular}




\begin{tabular}{|c|c|c|c|c|c|c|c|c|c|c|c|c|c|c|c|}
\hline \multirow[t]{2}{*}{$\begin{array}{l}\text { Los Arcos et } \\
\text { al. [26] }\end{array}$} & $\begin{array}{l}\text { Small- } \\
\text { sided } \\
\text { games }\end{array}$ & 6 & $1.83^{b}$ & 11 & $\begin{array}{l}3 \text { vs. } 3 \\
\text { and } 4 \text { vs. } \\
4 \text { under } \\
\text { various } \\
\text { conditions }\end{array}$ & 3 & 4 & 3 & \multirow[t]{2}{*}{$3-4$} & & \multirow{2}{*}{\multicolumn{2}{|c|}{85}} & \multirow[t]{2}{*}{ Yes and no } & $\begin{array}{l}<80 \% \text { to } \\
>90 \% \\
\text { HR max }\end{array}$ & \multirow{2}{*}{$\begin{array}{l}\text { min-1]) } \\
\text { Continuous } \\
\text { maximal } \\
\text { multistage } \\
\text { running } \\
\text { field test } \\
\text { (km*h-1) } \\
\text { Continuous } \\
\text { maximal } \\
\text { multistage } \\
\text { running } \\
\text { field test } \\
\left(\mathrm{km}^{*} \mathrm{~h}-1\right)\end{array}$} \\
\hline & $\begin{array}{l}\text { Interval } \\
\text { training }\end{array}$ & 6 & $1.83^{b}$ & 11 & & 3 & 4 & 3 & & & & & & $\begin{array}{l}90-95 \% \\
\text { HR max }\end{array}$ & \\
\hline \multirow[t]{2}{*}{$\begin{array}{l}\text { Radziminski } \\
\text { et al. [27] }\end{array}$} & $\begin{array}{l}\text { Small- } \\
\text { sided } \\
\text { games } \\
\text { group }\end{array}$ & 8 & 2 & 16 & $\begin{array}{l}\text { 3 vs.3, } \\
3 \text { vs.3 with } \\
\text { floating } \\
\text { neutral } \\
\text { player }\end{array}$ & 5 & 4 & 3 & $3-4$ & 30 & 18 & 540 & & $\begin{array}{l}90 \% \mathrm{HR} \\
\max \end{array}$ & \multirow{2}{*}{$\begin{array}{l}\text { Graded } \\
\text { cycle test } \\
\text { (Vo2 max } \\
{[(\mathrm{ml} \mathrm{kg}-1} \\
\text { min-1]) } \\
\text { Graded } \\
\text { cycle test } \\
(\text { Vo2 max } \\
{[(\mathrm{ml} \mathrm{kg}-1} \\
\text { min-1]) }\end{array}$} \\
\hline & $\begin{array}{l}\text { Running } \\
\text { group }\end{array}$ & 8 & 2 & 16 & & 5 & 4 & 3 & & & & & & $\begin{array}{l}90 \% \mathrm{HR} \\
\max \end{array}$ & \\
\hline \multirow[t]{2}{*}{$\begin{array}{l}\text { Safania et al. } \\
\text { [28] }\end{array}$} & $\begin{array}{l}\text { Small } \\
\text { sided } \\
\text { games } \\
\text { training }\end{array}$ & 6 & 3 & 18 & $\begin{array}{l}2 \text { vs. } 2 \text {, } \\
10 \times 15 \mathrm{~m} ; 3 \\
\text { vs. } 3,2-3 \\
\text { ball- } \\
\text { touches, } \\
25 \times 35 \mathrm{~m} \\
\text { field } \\
\text { dimension; } \\
4 \mathrm{vs.} 4,2 \\
\text { ball- } \\
\text { touches, } \\
40 \times 50 \mathrm{~m} \\
\text { field } \\
\text { dimension }\end{array}$ & 4 & 4 & 3 & $2-4$ & & & & No & $\begin{array}{l}70-95 \% \\
\text { HR max }\end{array}$ & $\begin{array}{l}12 \text { minute } \\
\text { running } \\
\text { test (Vo2 } \\
\max [(\mathrm{ml} \\
\mathrm{kg}-1 \\
\min -1])\end{array}$ \\
\hline & $\begin{array}{l}\text { Interval } \\
\text { training }\end{array}$ & 6 & 3 & 18 & & 4 & 4 & 3 & & & & & & $\begin{array}{l}70-95 \% \\
\text { HR max }\end{array}$ & $\begin{array}{l}12 \text { minute } \\
\text { running } \\
\text { test (Vo2 } \\
\max [(\mathrm{ml} \\
\mathrm{kg}-1 \\
\min -1])\end{array}$ \\
\hline
\end{tabular}


Legend: $\mathrm{HR} \max =$ maximum heart rate; Vo2 $\max =$ maximal oxygen uptake

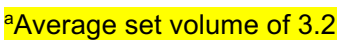

${ }^{\mathrm{b}}$ Analysed as 2 sessions per week in subgroup analyses 
Table 3 PEDro scale ratings

\begin{tabular}{|c|c|c|c|c|c|c|c|c|c|c|c|c|}
\hline Study & $1^{a}$ & 2 & 3 & 4 & 5 & 6 & 7 & 8 & 9 & 10 & 11 & Total \\
\hline $\begin{array}{l}\text { Eniseler et } \\
\text { al. [23] }\end{array}$ & 1 & 1 & 0 & 1 & 0 & 0 & 0 & 1 & 1 & 1 & 1 & 6 \\
\hline $\begin{array}{l}\text { Hill-Haas et } \\
\text { al. [24] }\end{array}$ & 1 & 1 & 0 & 1 & 0 & 0 & 0 & 0 & 1 & 1 & 1 & 5 \\
\hline $\begin{array}{l}\text { Impellizzeri } \\
\text { et al. [20] }\end{array}$ & 1 & 1 & 0 & 1 & 0 & 0 & 0 & 0 & 1 & 1 & 1 & 5 \\
\hline $\begin{array}{l}\text { Jastrzebski } \\
\text { et al. [25] }\end{array}$ & 1 & 0 & 0 & 1 & 0 & 0 & 0 & 1 & 1 & 1 & 1 & 5 \\
\hline $\begin{array}{l}\text { Los Arcos } \\
\text { et al. [26] }\end{array}$ & 1 & 1 & 0 & 1 & 0 & 1 & 0 & 1 & 1 & 1 & 1 & 7 \\
\hline $\begin{array}{l}\text { Radziminski } \\
\text { et al. [27] }\end{array}$ & 1 & 1 & 0 & 1 & 0 & 0 & 0 & 0 & 1 & 1 & 1 & 5 \\
\hline $\begin{array}{l}\text { Safania et } \\
\text { al. [28] }\end{array}$ & 1 & 0 & 0 & 0 & 0 & 0 & 0 & 1 & 1 & 1 & 1 & 4 \\
\hline
\end{tabular}

altem \#1 is not used to calculate final rating 
Table 4 Subgroup analyses

\begin{tabular}{|c|c|c|c|}
\hline Outcome or subgroup & Studies & Participants & $\begin{array}{c}\text { Estimated effect size } \\
\text { (mean }[95 \% \mathrm{Cl}] \text { ) }\end{array}$ \\
\hline Sets & 7 & $\overline{144}$ & \\
\hline$>4$ & 2 & 42 & $0.53[-0.52,1.58]$ \\
\hline$\leq 4$ & 5 & 102 & $-0.13[-0.52,0.26]$ \\
\hline Set duration & 7 & 144 & \\
\hline$\geq 4$ mins & 5 & 103 & $0.08[-0.49,0.64]$ \\
\hline$<4$ mins & 2 & 41 & $-0.07[-0.68,0.54]$ \\
\hline Recovery period between sets & 7 & 144 & \\
\hline$\geq 3$ mins & 5 & 103 & $0.14[-0.37,0.65]$ \\
\hline$<3$ mins & 2 & 41 & $-0.22[-0.84,0.40]$ \\
\hline Weeks & 7 & 144 & \\
\hline$\geq 8$ weeks & 3 & 71 & $0.45[-0.12,1.02]$ \\
\hline$<8$ weeks & 4 & 73 & $-0.33[-0.79,0.14]$ \\
\hline
\end{tabular}




\begin{tabular}{llll}
\hline Frequency & 7 & 144 & \\
$>2$ per week & 1 & 20 & $-0.40[-1.29,0.48]$ \\
2 per week & 6 & 124 & $0.11[-0.32,0.54]$ \\
\hline Total sessions & 7 & 144 & \\
$\geq 16$ sessions & 4 & 91 & $0.25[-0.32,0.83]$ \\
$<16$ sessions & 3 & 53 & $-0.30[-0.84,0.24]$ \\
\hline Age & 7 & 144 & \\
$\geq 15.7$ years & 4 & 90 & $-0.00[-0.42,0.41]$ \\
$<15.7$ years & 3 & 54 & $0.12[-0.85,1.10]$ \\
\hline Height & 7 & 144 & $0.05[-0.37,0.48]$ \\
$\geq 174.0 \mathrm{~cm}$ & 4 & 85 & $0.05[-0.95,1.04]$ \\
$<174.0 \mathrm{~cm}$ & 3 & 59 & $0.07[-0.43,0.57]$ \\
\hline Body mass & 7 & 144 & $0.04[-0.65,0.72]$ \\
$>62.1 \mathrm{~kg}$ & 3 & 63 & 81 \\
$\leq 62.1 \mathrm{~kg}$ & 4 & & \\
\hline
\end{tabular}

Positive effect size favours SSG 